\title{
A SAÚDE COMO UM SISTEMA SOCIAL: DO RISCO DA INEFETIVIDADE À JUDICIALIZAÇÃO EXCESSIVA EM MATÉRIA DE MEDICAMENTOS
}

\author{
Janaína Machado Sturza* \\ Aline Michele Pedron Leves* \\ Andressa Simmi Cavalheiro ${ }^{* * *}$
}

SUMÁRIO: Introdução; 20 direito fundamental à saúde na contemporaneidade: uma abordagem sistêmica e o risco da inefetividade de sua proteção; $3 \mathrm{~A}$ excessividade da judicialização da saúde: riscos, limites e possibilidades da concessão de medicamentos; 4 Considerações finais; Referências.

RESUMO: A sociedade se diferencia a partir dos seus processos evolutivos e das comunicações internas entre os sistemas que a compõe. Pensar na saúde como um sistema social consiste em uma importante questão para a construção de uma sociedade mais digna, pois as decisões a seu respeito contemplam um risco intrínseco na atualidade, sobretudo, no que concerne à inefetividade da proteção desse direito humano fundamental e ao excesso de judicialização em matéria de medicamentos. Desse modo, este artigo tem como objetivo contextualizar e analisar, por meio do método hipotético-dedutivo e da pesquisa bibliográfica, a temática do direito à saúde na sociedade contemporânea, a partir de uma abordagem sistêmica que rompe com os pressupostos tradicionais das ciências sociais, tendo como base de estudo e argumentação a teoria dos sistemas de Niklas Luhmann. A problemática reside na lacuna da inadequação organizacional da aplicação do direito à saúde frente às necessidades atuais. Como resultado, nota-se que a saúde pode ser analisada como um sistema social, permitindo-se reconhecer a sua complexidade e relação com o sistema jurídico. Portanto, conclui-se que a saúde, essencialmente no que se refere aos vínculos existentes entre o acesso à justiça para a obtenção de medicamentos e à efetividade da proteção desse direito em defesa da dignidade da pessoa humana, é um processo sistêmico que apresenta uma dimensão social e jurídica que deve ir além da cura e da prevenção de enfermidades, alcançando e proporcionando uma condizente qualidade de vida para os indivíduos que necessitam se adaptar à hipercomplexidade da sociedade contemporânea.

\footnotetext{
"Doutora em Direito, pela Escola Internacional de Doutorado em Direito e Economia Tullio Ascarelli, da Universidade de Roma Tre/Itália. Docente no Curso de Pós-graduação Stricto Sensu em Direitos Humanos e do curso de graduação em Direito da UNIJUí, Brasil. E-mail: janasturza@hotmail.com

*** Mestre em Direito pelo Programa de Pós-graduação em Direitoem Direitos Humanos da Universidade Regional do Noroeste do Estado do Rio Grande do Sul - UNIJUÍ, Brasil.

**** Mestre em Direito pelo Programa de Pós-graduação em Direito em Direitos Humanos da Universidade Regional do Noroeste do Estado do Rio Grande do Sul - UNIJUÍ, Brasil.
} 
PALAVRAS-CHAVE: Direito à saúde; Judicialização da saúde; Sistemas sociais.

\section{HEALTH AS A SOCIAL SYSTEM: FROM THE RISK OF INEFFECTIVENESS TO THE EXCESSIVE JUDICIALIZATION IN MEDICINE}

ABSTRACT: Society differentiates itself through evolution processes and internal communications between its systems. Health as a social system is a relevant issue for the construction of a worthier society. In fact, decisions deal with actual intrinsic risk especially with regard to the ineffectiveness of the protection of fundamental human rights and the excess in judicialization in drug distribution. Through the hypothetical, deductive and bibliographical research, current paper contextualizes and analyzes the right to health in contemporary society. Systemic approach is employed which ruptures the traditional presuppositions of social sciences and based on the arguments of Niklas Luhmann's system theory. The problem lies in the gap within the organizational inadequacy of the application of law to health in the wake of current needs. Health may be analyzed as a social system coupled to an acknowledgement of its complexity and relationship with the juridical system. Health, or rather, the existing links between access to justice for obtaining drugs and the effectiveness of protection of this right in defending the dignity of the human person, is a systemic process that presents a social and juridical dimension which goes beyond cure and the prevention of diseases. In fact, it provides adequate life quality for people that require adaptation to the hyper-complex stance of contemporary society.

KEY WORDS: Right to health; Judicialization of health; Social systems.

\section{LA SALUD COMO UN SISTEMA SOCIAL: DEL RIESGO DE LA INEFECTIVIDAD A LA JUDICIALIZACIÓN EXCESIVA EN MATERIA DE MEDICAMENTOS}

RESUMEN: La sociedad se diferencia a partir de sus procesos evolutivos y de las comunicaciones internas entre los sistemas que la componen. Pensar en la salud como un sistema social consiste en una importante cuestión para la construcción de una sociedad más digna, pues las decisiones a su respeto contemplan un riesgo intrínseco en la actualidad, sobre todo, en lo que concierne a la inefectividad de la protección de ese derecho humano fundamental y al exceso de judicialización en materia de medicamentos. De ese modo, en este artículo se tiene como objetivo contextualizar y analizar, por intermedio del método hipotético-deductivo y de la investigación bibliográfica, la temática del derecho a la salud en la sociedad contemporánea, a partir de un abordaje sistémico que rompe con los presupuestos 
tradicionales de las ciencias sociales, teniendo como base de estudio y argumentación la teoría delos sistemas de Niklas Luhmann. La problemática se ubica en la laguna de la inadecuación organizacional de la aplicación del derecho a la salud frente a las necesidades actuales. Como resultado, se nota que la salud puede ser analizada como un sistema social, permitiéndose reconocer su complexidad y relación con el sistema jurídico. Por lo tanto, se concluye que la salud, esencialmente en lo que se refiere a los vínculos existentes entre el acceso a la justicia para la obtención de medicamentos y a la efectividad de la protección de ese derecho en defensa de la dignidad de la persona humana, es un proceso sistémico que presenta una dimensión social y jurídica que debe ir más allá de la cura y de la prevención de enfermedades, alcanzando y proporcionando una coherente calidad de vida para los individuos que necesitan adaptarse a la híper complexidad de la sociedad contemporánea.

PALABRAS CLAVE: Derecho a la salud; Judicialización de la salud; Sistemas sociales.

\section{INTRODUÇÃO}

O mundo atual se evidencia cada vez mais complexo e interdependente. Na medida em que se verificaram os significativos avanços da modernização, a contemporaneidade trouxe consigo uma série de paradoxos e desafios oriundos dos processos da globalização social, econômica, política e cultural, os quais transformaram os sistemas de referência e passaram a exigir respostas às inúmeras complexidades que compõem o entorno social. Tais reflexos não deixaram à parte o direito à saúde, isso porque os impasses que o ameaçam e colocam em risco a saúde pública interessam a todos os indivíduos e não apenas a grupos isoladamente considerados da sociabilidade humana.

Nessa nova conjuntura, a saúde como um sistema social passou a assumir um papel de extrema relevância, essencialmente, no que concerne à construção de uma sociedade mais digna, que se diferencia funcionalmente pelos processos evolutivos pela qual perpassa e por meio das comunicações existentes entre os sistemas que a compõe. Foi a partir da segunda metade do século XX e do início do século XXI que se modificaram os modelos de referência soberanista e territorial da modernidade e, por conseguinte, a sociabilidade humana passou a constatar, cada vez mais, a necessidade de uma ampla proteção aos direitos fundamentais.

Dessa forma, a inclusão do direito à saúde como um direito de todos e 
dever do Estado na Constituição Federal do Brasil de $1988^{\circ 4}$, constituiu um avanço significativo na história da sociedade brasileira, isso porque, pela primeira vez, a saúde passou a ser reconhecida de maneira igualitária e universal. Oriunda de amplos debates que envolveram tanto o Estado como a sociedade civil, a previsão constitucional do direito à saúde trouxe consigo a possibilidade de reivindicação individualizada, com vistas à obtenção de uma assistência universalizada. À vista disso, verifica-se que o papel desempenhado pelo Poder Judiciário no tocante à proteção e à efetivação do direito à saúde vem assumindo, cada vez mais, a posição dos entes públicos estatais no cumprimento dos seus deveres prestacionais.

O principal desafio evidencia-se justamente na formulação de um conjunto de estratégias sociopolíticas, associadas aos mecanismos e instrumentos estatais voltados ao cumprimento de políticas públicas que garantam o aperfeiçoamento dos sistemas de saúde e de justiça, com vistas a assegurar o direito à saúde em defesa da dignidade da pessoa humana. Assim, a soma dos riscos da inefetividade da proteção à saúde, a precariedade das políticas públicas voltadas para a prevenção de doenças e a falta de eficiência do Sistema Único de Saúde brasileiro, exigem do Estado uma gama de responsabilidades, posto que a sociedade fica à mercê do poder estatal e, na maior parte das vezes, os indivíduos precisam buscar via judicial o cumprimento de um dever constitucional imposto ao Estado, para ter assegurado um direito público subjetivo: a saúde. Tudo isso ocasiona a judicialização excessiva, como é o caso das demandas que pleiteiam a concessão de medicamentos e tratamentos.

Nesse cenário, baseado na teoria sistêmica desenvolvida por Niklas Luhmann, o presente artigo objetiva contextualizar e analisar a temática do direito à saúde na contemporaneidade, sobretudo, no que se refere à problemática do risco da sua inefetividade, o qual acarreta um excesso de judicialização das demandas em matéria de medicamentos diante da notável lacuna da inadequação organizacional para assegurar a universalidade da saúde na sociedade atual. Com efeito, através do emprego do método hipotético-dedutivo - que parte de uma premissa maior a fim de estabelecer uma conclusão específica acerca do tema proposto - e da técnica de pesquisa bibliográfica, verificou-se como resultado que a saúde pode (e deve) ser analisada como um sistema social.

Assim sendo, estabelece-se uma relação direta com o sistema jurídico, especialmente no que diz respeito ao acesso à justiça para a obtenção de

${ }^{04}$ BRASIL. Constituição da República Federativa do Brasil de 1988. Presidência da República. Disponível em: http://planalto.gov.br/ccivil_03/constituicao/constituicao.htm. Acesso em: 26 fev. 2018. 
medicamentos/tratamentos e à construção de uma sociedade que privilegie a vida e a efetividade da proteção do direito à saúde em defesa da dignidade humana. Portanto, resta evidente o reconhecimento da saúde como um processo sistêmico, além de buscar a cura e a prevenção de enfermidades, também deve promover a qualidade de vida para os indivíduos, especialmente neste contexto social atual, de extrema complexidade e interdependência.

\section{O DIREITO FUNDAMENTAL À SAÚDE NA CONTEMPORANEIDADE: UMA ABORDAGEM SISTÊMICA E O RISCO DA INEFETIVIDADE DE SUA PROTEÇÃO}

Desde os tempos mais remotos da história da humanidade, evidenciase que a busca pela saúde já consistia em uma realidade e atingia uma dimensão de preocupação que era exteriorizada socialmente pelo medo da morte. As civilizações antigas entendiam a saúde como uma forma de eliminação dos males e enfermidades que acometiam os indivíduos e ameaçavam a sua sobrevivência, isso porque, as epidemias que se alastravam rapidamente poderiam alcançar proporções imensuráveis e reduzir significativamente a espécie humana. $O$ primeiro conceito de saúde advém da Grécia antiga, mais especificamente, dos gregos da cidade-Estado de Esparta, os quais formularam a máxima Mens Sana In Corpore Sano, que significa: o equilíbrio do corpo e da mente humana em proporções harmoniosas. Entretanto, foi com a chegada da Idade Média que se verificou um significativo retrocesso nas questões relativas à saúde, isso porque, com a ocorrência de inúmeras pestes e surtos epidêmicos, os doentes passaram a ser encarados como um mal da sociedade e, por esse motivo, deveriam ser afastados do convívio social ${ }^{05}$. Para Ulrich Beck, "a ameaça que as doenças e a morte representavam para o indivíduo e sua família, bem como a fome e as epidemias para as comunidades, eram bem maiores na Idade Média do que hoje em dia"06.

Dessa maneira, apesar da formulação de mecanismos voltados para a proteção e a manutenção da saúde datar do início dos séculos, as concepções modernas da saúde pública somente foram evidenciadas no decorrer da Revolução Industrial dos séculos XVIII e XIX. Esses entendimentos, por sua vez, se intensificaram durante

\footnotetext{
${ }^{05}$ SCHWARTZ, Germano André Doederlein. Direito à Saúde: efetivação em uma perspectiva sistêmica. Porto Alegre: Livraria do Advogado, 2001.

${ }^{06}$ BECK, Ulrich. Sociedade de risco mundial: em busca da segurança perdida. Tradução de Marian Toldy e Teresa Toldy. Lisboa: Edições 70, 2015, p. 22.
} 
o século XX, com o surgimento do Welfare State (Estado de Bem-estar Social) e o término das duas grandes guerras mundiais que impulsionaram a criação de organismos internacionais, tais como a Organização Mundial da Saúde (OMS) e, por conseguinte, a elaboração de uma definição contemporânea da saúde ${ }^{07}$.

Perpassada a era industrial e as alterações ocorridas internacionalmente após o período de guerras que inquietou as nações no século passado, nota-se que as transformações da contemporaneidade, oriundas dos processos da globalização, são ainda mais céleres e profundas do que se poderia prever em qualquer outro momento histórico. Esse cenário contribuiu significativamente para a reformulação da ideia de saúde e trouxe consigo a compreensão dessa enquanto um sistema social altamente complexo.

Nesse panorama relegado à sociedade atual, as relações mundiais contraíram relevante complexidade, polaridade incerta e uma expansão do vínculo de cooperação e interdependência entre os povos. Tais mudanças alicerçaram novas possibilidades e alternativas mundiais mais integradas, corroborando para a construção de uma nova ordem social repleta de contradições. Fato é que a globalização consiste em uma daquelas noções difíceis de prescindir, sempre que se impõe o desafio de decifrar a complexidade do mundo e as características fundamentais da contemporaneidade. É notório que a terminologia não encerra somente grandes ambiguidades, não restando a menor dúvida de que a configuração do planeta como um sistema global consiste num dos mais expressivos acontecimentos do processo histórico civilizacional.

Verifica-se que o novo século traz à tona um intenso paradoxo jamais vivido em âmbito mundial: por um lado, evidencia-se o extraordinário avanço modernizador das renovadas e complexas tecnologias; por outro lado, destaca-se a contradição existente na mundializaçãa $0^{08}$ da vida humana, na qual dois opostos se atraem inevitavelmente - a homogeneização política, econômica e cultural, bem como a desagregação dos centros de referência da sociedade atual. Nesse sentido, Gilmar Bedin destaca que o início do novo "século XXI está envolvido com o surgimento e a consolidação de fluxos que não respeitam fronteiras. Em

$\overline{{ }^{77} \text { CURY, Ieda Tatiana }}$. Direito fundamental à saúde: Evolução, Normatização e Efetividade. Rio de Janeiro: Lumen Juris, 2005. FIGUEIREDO, Mariana Filchtiner. Direito fundamental à saúde: parâmetros para sua eficácia e efetividade. Porto Alegre: Livraria do Advogado, 2007.

${ }^{08}$ Esta expressão, oriunda da doutrina francesa, relaciona-se à expansão dos direitos humanos na sua dimensão política, jurídica e social. Nesse sentido, a mundialização diverge do termo globalização, uma vez que esse se relaciona, mais especificamente, com os interesses de ordem econômica. 
outras palavras, está preocupado com os problemas oriundos da emergência e da estruturação do domínio da política e da economia mundiais.” ${ }^{\circ}$.

Sob a perspectiva aberta pela globalização, tudo se encontra ainda mais ativo e atrelado mundialmente, sendo conferidos novos significados ao indivíduo e à sociedade, aos grupos e classes, às etnias e minorias, às ideologias e utopias. Em virtude desse fenômeno, os Estados e as sociedades pós-modernas apresentam-se, atualmente, imersos em uma complexidade de condições mundiais sem qualquer precedente histórico: isso porque nunca antes as fronteiras estatais verificaram-se tão inócuas e transponíveis; ademais, percebe-se um irrefreável avanço tecnocientífico, bem como a multiplicação dos riscos, das inseguranças, das catástrofes e das moléstias e epidemias incuráveis em escala planetária. Por conseguinte, pode-se afirmar que a globalização permite à civilização humana "pensar o presente, rebuscar o passado e imaginar o futuro" ${ }^{10}$.

Reportando-se, sobretudo, à economia, vale ressaltar que a globalização abrange ainda todos os outros sistemas autopoiéticos e autorreferentes, os quais englobam diversas áreas da atividade humana que repercutem diretamente na sociedade, ampliando as diferenciações funcionais num ritmo jamais verificado e tornando as identidades mais efêmeras e polimorfas. Destarte, a partir dessa vasta gama de transformações mundiais, resta evidente que a humanidade está apenas do início de uma sociedade altamente complexa, repleta de riscos e permanentemente em evolução. Em uma perspectiva sistêmica, pode-se afirmar que se vivencia um momento de hipercomplexidade, uma vez que existe a alternativa de se recorrer aos diferentes subsistemas que compõem a sociedade, os quais se comunicam para determinar um contingente de possibilidades que permitam o enfrentamento de questões específicas na contemporaneidade, como é o caso da proteção e promoção da saúde pública ${ }^{11}$.

Nessa linha de pensamento, a teoria dos sistemas sociais, desenvolvida por Niklas Luhmann ${ }^{12}$ para que a sociedade possa ser melhor observada, fundamenta-se na ideia de que a organização de um sistema - seja esse econômico, jurídico ou político

\footnotetext{
${ }^{09}$ BEDIN, Gilmar Antonio. A sociedade internacional e o século XXI: em busca da construção de uma ordem mundial justa e solidária. Ijuí: Unijuí, 2001. p. 32.

${ }^{10}$ IANNI, Octavio. A sociedade global. Rio de Janeiro: Civilização Brasileira, 1996. p. 9.

${ }^{11}$ SCHWARTZ, Germano André Doederlein. Direito à Saúde: efetivação em uma perspectiva sistêmica. Porto Alegre: Livraria do Advogado, 2001. VIAL, Sandra Regina Martini. O sistema social da saúde: conceito, limites e possibilidades. Cadernos Ibero-Americanos de Direito Sanitário, v. 3, n. 1, jan./jun., p. 68-83, 2014. Disponível em: http://dx.doi.org/10.17566/ciads.v3i1.19. Acesso em: 28 fev. 2018.

${ }^{12}$ LUHMANN, Niklas. El derecho de la sociedad. Tradução de Javier Torres Nafarrate. México: Herder, 2005.
} 
- não se baseia em indivíduos, mas em comunicações, sendo caracterizada como autorreferencial e autorreprodutiva. Isso significa que os sistemas serão analisados a partir de um viés autopoiético, operativamente fechados e cognitivamente abertos, capazes de se constituírem ou reconstituírem-se continuamente com base em seus próprios elementos (processos, normas, atos e identidade). Essa autorreferência viabiliza que os sistemas modifiquem e influenciem a sociedade, alterando-se simultaneamente de acordo com o seu código binário e, inclusive, permitindo uma construção dinamicamente adequada do grande sistema social.

Conforme Gunther Teubner, verifica-se, de fato, uma "interpenetração" entre os distintos sistemas que compõe a sociedade. Isso não poderia ser diferente no que concerne à relação existente entre a saúde e o direito, no sentido da proteção e aplicação desse direito humano fundamental ${ }^{13}$. Torna-se possível, então, encontrar respostas para as questóes essenciais nascidas do risco da inefetividade da proteção do direito à saúde a partir da autopoiese ${ }^{14}$, ou seja, da versão luhmaniana da sistemática, isso porque, da mesma forma que o direito, a saúde também passa a ser estabelecida como um sistema social autopoiético, o qual se reconstrói por meio da sua clausura operacional e da abertura cognitiva, sendo "orientada pelo seu código próprio Saúde/Enfermidade" ${ }^{15}$. Portanto, são perceptíveis o consequente acoplamento estrutural entre os referidos sistemas - saúde e direito - e a comprovação da necessária correlação de ambos.

A saúde como um sistema diferenciado funcionalmente incorpora a "grande rede ou malha de comunicações chamada sociedade"16 e sofre irritações do ambiente externo, ou seja, do seu entorno composto pelos demais sistemas

\footnotetext{
13 TEUBNER, Gunther. O Direito como Sistema Autopoiético. Tradução de José Engrácia Antunes. Lisboa: Fundação Calouste Gulbenkian, 1993.

${ }^{14}$ A origem etimológica do termo autopoiesis é proveniente do grego, em que auto significa próprio e poiesis significa produção. Portanto, a palavra autopoiese remete-se, no âmbito da teoria sistêmica, à lógica própria da autoprodução e da autorreferência, no sentido de que os diferentes sistemas sociais se (re)criam circularmente a partir dos elementos que o compõe. Para Niklas Luhmann (1994, p. 20), autopoiesis "significa que um sistema reproduz os elementos de que é constituído, em uma ordem hermético-recursiva, por meio de seus próprios elementos", ou seja, um sistema social possui processos, normas, princípios e atos que se auto reproduzem. In: LUHMANN, Niklas. O Enfoque Sociológico da Teoria e Prática do Direito. Tradução de Cristiano Paixão, Daniela Nicola e Samantha Dobrowolski. In: Sequência. Estudos Jurídicos e Políticos - PPGD UFSC. n. 28, jun., p. 15-29. Florianópolis: UFSC, 1994. Disponível em: https://periodicos.ufsc.br/index.php/ sequencia/article/view/15871/14360. Acesso em: 02 mar. 2018.

15 SCHWARTZ, Germano André Doederlein. O tratamento jurídico do risco no direito à saúde. Porto Alegre: Livraria do Advogado, 2004. p. 20.

${ }^{16}$ VIAL, Sandra Regina Martini. O sistema social da saúde: conceito, limites e possibilidades. Cadernos IberoAmericanos de Direito Sanitário, v. 3, n. 1, jan./jun., p. 68-83, 2014. Disponível em: http://dx.doi.org/10.17566/ ciads.v3i1.19. Acesso em: 28 fev. 2018. p. 71.
} 
sociais $^{17}$. É justamente a dicotomia entre sistema e entorno que torna possível a autorreferência, em outras palavras: a autopoiese de um sistema que é considerado tanto autônomo como interdependente do entorno. No entendimento de Fritjof Capra e Pier Luigi Luisi, o interior de um sistema configura-se extremamente complexo no sentido de que entabula redes comunicacionais próprias a partir dos seus elementos e, simultaneamente, remanesce aberto em relação aos estímulos sofridos pelo ambiente externo ${ }^{18}$.

Por isso, pensar na saúde como um elemento integrante do sistema social significa reconhecer a sua complexidade e a relação com outros sistemas, como no caso do direito. Germano Schwartz evidencia que a saúde necessita de proteção e de regulamentação a partir do momento em que "reproduz-se e se relaciona com os demais sistemas sociais"19 e sofre irritações da complexidade do entorno. Portanto, pode-se afirmar que somente se torna possível compreender a positividade do direito à saúde, quando analisados os elementos operacionais dos sistemas da saúde e do direito, voltados para a efetivação desse direito fundamental na sociedade contemporânea.

Por conseguinte, nota-se que a teoria dos Sistemas Sociais de Luhmann ${ }^{20}$ apresenta elementos que são considerados suficientes para afirmar que, "no processo evolutivo, a saúde foi aprimorando suas comunicações e estruturando-se como um subsistema social, ou em sistema social"11, autopoiético, operativamente fechado e cognitivamente aberto. Verifica-se, então, que a teoria sistêmica se estabelece como base de sustentação da ideia de que a saúde consiste em um sistema social, até porque, esse é autorreferente - produz a si próprio - a partir de uma operação

\footnotetext{
${ }_{17}$ Os sistemas sociais dispõem de uma lógica própria a partir dos elementos que os compõem, entretanto, esses não se evidenciam desconectados do entorno, o qual é capaz de produzir ruídos que irritam comunicacionalmente os sistemas. Desse modo, em virtude da abertura cognitiva que possibilita as comunicações, os sistemas realizam uma filtragem e absorção das influências do ambiente externo, por meio de códigos binários intrínsecos (sim/não-sim), selecionando e trazendo as especificidades para o âmbito interno, onde as questões/estímulos serão (re)processadas na lógica da clausura operacional autopoiética. Portanto, devido ao fechamento operativo interno de um sistema, torna-se possível a sua estabilidade; e a abertura externa cognitiva, viabiliza as comunicações com os demais sistemas que compõe o entorno social LUHMANN, Niklas. El derecho de la sociedad. Tradução de Javier Torres Nafarrate. México: Herder, 2005.

${ }^{18}$ CAPRA, Fritjof; LUISI, Pier Luigi. A visão sistêmica da vida: uma concepção unificada e suas implicações filosóficas, políticas, sociais e econômicas. Tradução de Mayra Teruya Eichemberg e Newton Roberval Eichemberg. São Paulo: Cultrix, 2014.

19 SCHWARTZ, Germano André Doederlein. O tratamento jurídico do risco no direito à saúde. Porto Alegre: Livraria do Advogado, 2004. p. 23.

${ }^{20}$ LUHMANN, Niklas. El derecho de la sociedad. Tradução de Javier Torres Nafarrate. México: Herder, 2005.

${ }^{21}$ VIAL, Sandra Regina Martini. O sistema social da saúde: conceito, limites e possibilidades. Cadernos IberoAmericanos de Direito Sanitário, v. 3, n. 1, jan./jun. p. 68-83, 2014. Disponível em: http://dx.doi.org/10.17566/ ciads.v3i1.19. Acesso em: 28 fev. 2018. p. 75.
} 
comunicativa e de auto-observação entre as distinções do sistema e do entorno (ambiente externo).

Nesse viés, a abertura cognitiva possibilita uma irritação interna do sistema da saúde, o qual leva em consideração a compreensão reflexiva a partir da observância e interferência do complexo entorno social. Nota-se que o sistema da saúde recebe, constantemente, irritações e influências de outros sistemas sociais, especialmente, do direito. Tal fato pode ser verificado, de maneira ainda mais intensa, nos países periféricos, como é o caso do Brasil, em que "o direito é constantemente 'chamado' a decidir sobre questões 'não decididas' por outros subsistemas"22. Assim, pode-se afirmar que a correlação entre os sistemas da saúde e do direito permite a elaboração das normas voltadas à proteção da saúde, as quais se originam de um processo interno reflexivo apreendido pelo sistema da saúde e que perpassa por irritações externas ocasionadas pelo sistema jurídico.

Uma manifestação dessa irritação pode ser verificada materialmente no que se refere à judicialização da saúde, processo pelo qual o judiciário atua no sentido de assegurar a efetividade da proteção do direito à saúde em defesa da dignidade da pessoa humana. Foi no final da década de 1990 que se observou excessivo aumento das demandas judiciais vinculadas à saúde no Brasil, onde mais de $50 \%$ das ações buscadas individualmente para requerer o cumprimento do dever constitucional imposto ao Estado em garantir o direito à saúde de maneira igualitária e universal. Portanto, torna-se evidente a relação existente entre os sistemas sociais da saúde e do direito, isso porque, cada um deles realiza operações internas específicas, de acordo com os seus próprios elementos e, constantemente, produz irritações recíprocas ${ }^{23}$.

Além disso, destaca-se que o sistema do direito enfrenta ampla gama de dificuldades na edição de normas vinculantes para os distintos campos da vida em sociedade e, por vezes, os "direitos individuais, direitos políticos e direitos sociais, há tempos institucionalizados, são crescentemente 'flexibilizados' ou 'desconstitucionalizados'”'4, em virtude das ingerências do sistema econômico nas ordens jurídica, política e social. Nesse sentido, o sistema da saúde não permanece ileso, isso porque a proteção do direito à saúde não é uma realidade efetiva em solo

\footnotetext{
22 VIAL, Sandra Regina Martini. Construção do sistema social da saúde a partir da Teoria Sistêmica de Niklas Luhmann. Revista de Direito Sanitário, v. 16, n.1, mar./jun., p. 112-127, 2015. Disponível em: http://dx.doi. org/10.11606/issn.2316-9044.v16i1p112-127. Acesso em: 27 fev. 2018. p. 120.

23 VIAL, Sandra Regina Martini. O sistema social da saúde: conceito, limites e possibilidades. Cadernos IberoAmericanos de Direito Sanitário, v. 3, n. 1, jan./jun., p. 68-83, 2014. Disponível em: http://dx.doi.org/10.17566/ ciads.v3i1.19. Acesso em: 28 fev. 2018.

${ }^{24}$ FARIA, José Eduardo. O direito na economia globalizada. São Paulo: Malheiros, 2002. p. 15.
} 
brasileiro. Assim, o referido sistema necessita, cada vez mais, de normas capazes de redefinir os principais campos de atuação estatal, de tal modo que a democracia possa realizar-se plenamente, assegurando a efetividade dos direitos fundamentais e com vistas à construção de uma sociedade mais justa.

Acerca da problemática da eficácia e da efetividade dos direitos fundamentais, Teubner ${ }^{25}$ discorre no sentido de que esses são considerados imprescindíveis nos contextos sociais em que ocorrem ameaças à integridade dos indivíduos por parte do Estado em não os assegurar, como também, de instituições privadas. O autor relaciona essas "ameaças por meio de matrizes comunicativas anônimas (Instituições, Discursos, Sistemas) à integridade de instituições, pessoas e indivíduos" ${ }^{26}$. Notase, portanto, que os direitos fundamentais, tais como a saúde, se configuram como instrumentos sociais e jurídicos reativos às tendências expansionistas dos complexos sistemas sociais, em especial, do político e do econômico, caracterizando-se como indispensáveis.

Fato é que, no Brasil, "nem todos têm saúde, mas todos têm direito a ela (art. 196, CF/88)"' ". À vista disso, pode-se afirmar que as irritações e ingerências sofridas pelo sistema do direito em meados de 1980, acarretaram na constitucionalização do direito à saúde e possibilitaram os acoplamentos estruturais, uma vez que é justamente por meio da previsão constitucional que se reconhece o dever estatal de assegurar universalmente a saúde. Por isso, desataca-se que o sistema do direito estimula a atuação do sistema da política, muitas vezes, por meio a aplicação das políticas públicas de saúde. À vista disso, é evidente que a comunicação entre os sistemas jurídico e político possui ampla relevância, dado que a efetividade da saúde necessita desse acoplamento frente às evoluções, às complexidades e às contingências da contemporaneidade que acentuam o risco e a convivência com as incertezas.

Nesse sentido, "a necessidade de intervenção estatal para assegurar as condições mínimas de sobrevivência digna do homem" ${ }^{28}$ resultou na criação dos direitos sociais, dentre esses, o direito à saúde. Contudo, a inefetividade do referido

25 TEUBNER, Gunther. Fragmentos Constitucionais: constitucionalismo social na globalização. São Paulo: Saraiva, 2016.

${ }^{26}$ TEUBNER, Gunther. Fragmentos Constitucionais: constitucionalismo social na globalização. São Paulo: Saraiva, 2016. p. 257.

27 SCHWARTZ, Germano André Doederlein. O tratamento jurídico do risco no direito à saúde. Porto Alegre: Livraria do Advogado, 2004. p. 25.

${ }^{28}$ CURY, Ieda Tatiana. Direito fundamental à saúde: Evolução, Normatização e Efetividade. Rio de Janeiro: Lumen Juris, 2005. p. 38. 
direito pode ocasionar inúmeros riscos à sociedade, uma vez que se parte do pressuposto de que a saúde consiste, primeiramente, em um bem público de todos. Para Schwartz, a saúde pública evidencia-se como uma "meta a ser alcançada e que varia de acordo com sua própria evolução e com o avanço dos demais sistemas com os quais se relaciona, em especial o Estado e a própria sociedade" ${ }^{29}$. Por sua vez, a qualidade de vida dos seres humanos também consiste em um processo sistêmico, advindo da teoria luhmaniana, visto que "o conceito de saúde age diretamente sobre o conceito de qualidade de vida" ${ }^{30}$.

É notável, portanto, que a saúde é entendida e estudada de acordo com a perspectiva da qualidade de vida, que passa a ser garantida por meio da promoção, da prevenção e da cura de doenças por um sistema que age em prol de toda a sociedade e do cidadão. A noção de proteção da saúde pelo Estado resulta de "uma longa evolução na concepção não apenas do direito, mas da própria ideia do que seja a saúde, em si mesma considerada"’1 ${ }^{1}$. Pode-se afirmar, então, que existem inúmeros riscos intrínsecos no que concerne à inefetividade da proteção do direito humano fundamental à saúde diante de toda a trama da globalização que compreende o processo civilizatório da contemporaneidade.

Assim, Olinda Luiz e Amélia Cohn afirmam que, no âmbito da saúde, o "risco individualiza-se no [...] 'autogerenciamento': supõe-se que as pessoas, valendo-se de informações suficientes, adaptem seus comportamentos, eliminando todos os riscos e assim alcancem a saúde plena"32. No entanto, é evidente o dever do Estado em garantir a efetividade do direito à saúde, de forma planejada e equilibrada com o orçamento público, de tal modo que as demandas judiciais não sobrecarreguem o Poder Judiciário.

Por outro viés, Luhmann ${ }^{33}$ entende que o célere avanço dos efeitos da globalização consiste em um relevante debate e relaciona-se à temática do risco nas políticas públicas, especificamente, na área da saúde. À vista disso, o aludido autor afirma que o "conceito de saúde na distinção saúde-enfermidade [...] funciona

${ }^{29}$ SCHWARTZ, Germano André Doederlein. Direito à Saúde: efetivação em uma perspectiva sistêmica. Porto Alegre: Livraria do Advogado, 2001. p. 39.

${ }^{30}$ Ibidem, 2001. p. 40.

${ }^{31}$ FIGUEIREDO, Mariana Filchtiner. Direito fundamental à saúde: parâmetros para sua eficácia e efetividade. Porto Alegre: Livraria do Advogado, 2007. p. 77.

32 LUIZ, Olinda do Carmo; COHN, Amélia. Sociedade de risco e risco epidemiológico. Cadernos de Saúde Pública. Rio de Janeiro, v. 22, n. 11, p. 2339-2348, 2006. Disponível em: http://dx.doi.org/10.1590/S0102311X2006001100008. Acesso em: 04 mar. 2018. p. 2340.

${ }_{33}$ LUHMANN, Niklas. Sociología del Riesgo. México: Universidad Iberoamericana, 1992. Disponível em: https:// analisisinstitucionaluba.files.wordpress.com/2013/08/sociologia-del-riesgo-niklas-luhmann.pdf. Acesso em: 28 fev. 2018. 
exclusivamente como um conceito de reflexão [...] para as demandas sociais que, dependendo do nível variável de exigência, abrem o caminho para o cálculo de riscos" ${ }^{\text {”3 }}$ (Tradução nossa). Portanto, para Luhmann "no que diz respeito à saúde isso significa que a percepção de risco e o peso da decisão são transferidos para a vida cotidiana" ${ }^{35}$ (Tradução nossa) em sociedade, a qual é composta por vários sistemas que agem com vistas à melhor organização e estruturação da ordem pública para a garantia do cumprimento dos deveres em defesa dos direitos sociais.

Contudo, nessa era da globalização, em que tudo é mais efêmero e dotado de liquidez, Ingo Wolfgang Sarlet observa que "mesmo com os inegáveis avanços no sentido da busca da máxima efetivação de direitos fundamentais", como no caso em estudo (da saúde), a verdade é que a sociedade está muito distante, "e isso no terceiro milênio - de ter solucionado a miríade de problemas e desafios que a matéria suscita" ${ }^{36}$. Isso porque, um dos principais entraves da atualidade reside justamente na efetividade dos direitos fundamentais, sobretudo, em relação aos direitos sociais que detém uma dimensão prestacional por parte do Estado e, por esse motivo, necessitam muitas vezes da intervenção do Poder Judiciário para que sejam socialmente assegurados e implementados.

Assim, em um Brasil onde a Constituição Federal reconhece o direito de todos os indivíduos à saúde, se observa a ineficácia de fato da proteção desse direito fundamental, especialmente, em virtude da inadequação organizacional de aplicação do direito saúde na sociedade contemporânea, repleta de desafios e paradoxos ${ }^{37}$. Portanto, verifica-se que a teoria dos sistemas sociais de Niklas Luhmann é capaz de oferecer um instrumento teórico apto às necessidades sociais, especialmente, no tocante ao direito à saúde, em virtude do processo de acoplamento estrutural entre os sistemas da saúde e do direito, que visam à construção de uma ordem social que privilegie a vida humana e a efetividade dos direitos humanos fundamentais.

\footnotetext{
34 Texto original: "el concepto de salud en la distinción enfermo-sano [...] funge exclusivamente como un concepto de reflexión [...] para las exigencias sociales que, según sea el nivel variable de la exigencia, se abre paso en el cálculo de riesgos." In: LUHMANN, Niklas. Sociología del Riesgo. México: Universidad Iberoamericana, 1992. Disponível em: https://analisisinstitucionaluba.files.wordpress.com/2013/08/sociologiadel-riesgo-niklas-luhmann.pdf. Acesso em: 28 fev. 2018. p. 36.

35 Texto original: "con respecto a la salud esto quiere decir que la percepción de riesgo y la carga de la decisión, se trasladan a la vida cotidiana." In: LUHMANN, Niklas. Sociología del Riesgo. México: Universidad Iberoamericana, 1992. Disponível em: https://analisisinstitucionaluba.files.wordpress.com/2013/08/sociologiadel-riesgo-niklas-luhmann.pdf. Acesso em: 28 fev. 2018. p. 50.

36 SARLET, Ingo Wolfgang. A eficácia dos direitos fundamentais: uma teoria geral dos direitos fundamentais na perspectiva constitucional. 10. ed. rev. atual. e ampl. Porto Alegre: Livraria do Advogado, 2009. p. 21.

${ }^{37}$ BRASIL. Constituição da República Federativa do Brasil de 1988. Presidência da República. Disponível em: http://planalto.gov.br/ccivil_03/constituicao/constituicao.htm. Acesso em: 26 fev. 2018.
} 


\section{A EXCESSIVIDADE DA JUDICIALIZAÇÃO DA SAÚDE: RISCOS, LIMITES E POSSIBILIDADES DA CONCESSÃO DE MEDICAMENTOS}

A saúde como um direito fundamental consiste em um tema presente no cotidiano da sociedade contemporânea, seja pela busca de mecanismos considerados essenciais para a sua manutenção ou pela busca de tratamentos adequados para a cura de enfermidades adquiridas pelos indivíduos em virtude das mais variadas razões. Apesar disso, falar de saúde não é tão simples quanto parece, uma vez que isso pressupõe a existência da definição do que de fato é a saúde e, inclusive, do que é ser saudável. Propriamente dita, destaca-se que a temática em estudo costuma ser tratada com extrema relevância, isso porque, é evidente que o sistema social da saúde abarca um conjunto amplo de fatores.

A Constituição Federal brasileira de 1988 consagrou, por seu teor e sem quaisquer precedentes no país, a promessa de um Estado Social, detendo entre seus fundamentos, a dignidade da pessoa humana, os valores sociais do trabalho e da livre iniciativa, o pluralismo político e, apresentando uma grande inovação ao elencar no rol dos direitos sociais, o direito à saúde. A própria formulação estrutural da nova Carta, enunciando os direitos fundamentais logo em seu início, anteriormente à organização estatal, já denota um pioneiro espírito de valorização da pessoa e de visualização do Estado como garantidor das políticas públicas ${ }^{38}$.

O reconhecimento da saúde na sociedade brasileira como um direito de todos e dever do Estado se tornou um marco de ampla importância e, a partir disso, foi projetada uma nova lógica da política pública de saúde no país. Diferentemente dos documentos anteriores, os quais reduziam a extensão do conceito de direito à saúde - vinculando-o somente à assistência médica que era garantida a uma parcela pequena da sociedade -, a nova definição de saúde revelada pela Constituição Federal do Brasil, em seu art. 196, é bastante abrangente ao prever que "a saúde é assegurada mediante políticas públicas sociais e econômicas que visem a redução do risco de doenças e outros agravos"39. Além do mais, está incluída nessa conceituação: o direito "ao acesso universal ${ }^{40} \mathrm{e}$ igualitário às ações e serviços para sua promoção, proteção e recuperação".

\footnotetext{
38 BRASIL. Constituição da República Federativa do Brasil de 1988. Presidência da República. Disponível em: http://planalto.gov.br/ccivil_03/constituicao/constituicao.htm. Acesso em: 26 fev. 2018.

39 BRASIL. Constituição da República Federativa do Brasil de 1988. Presidência da República. Disponível em: http://planalto.gov.br/ccivil_03/constituicao/constituicao.htm. Acesso em: 26 fev. 2018.

40 BRASIL. Constituição da República Federativa do Brasil de 1988. Presidência da República. Disponível em: http://planalto.gov.br/ccivil_03/constituicao/constituicao.htm. Acesso em: 26 fev. 2018.
} 
É verificável que a Carta Magna brasileira levou em consideração o primeiro conceito formulado pela Organização Mundial de Saúde (OMS), em sua Constituição de 1946, a qual designou que a saúde consiste em "estado de completo bem-estar físico, mental e social e não apenas a ausência de doenças" ${ }^{\prime \prime 1}$. Daí, portanto, a sociedade do segundo pós-guerra passou a ter a noção de que além da necessidade de se curar as enfermidades, dever-se-ia existir um cuidado especial em relação a todos os indivíduos a fim de evitar o adoecimento e, inclusive, de manter um equilíbrio entre o corpo e a mente dos seres humanos - da mesma forma como preconizavam os gregos da antiguidade -, retomando-se a ideia da qualidade de vida. Além disso, na contemporaneidade, a saúde é considerada, sobretudo, um direito humano inalienável, visto que é assim assegurada pela Declaração Universal dos Direitos Humanos de 1948, consistindo em um elemento fundamental da cidadania, diretamente conectado aos preceitos que defendem a dignidade da pessoa humana.

Nesse sentido, em uma constante busca do estado de bem-estar social e para efeitos de aplicação do art. 196 da Constituição Federal de 1988², Schwartz entende que a saúde consiste em "um processo sistêmico que objetiva a prevenção e cura de doenças, ao mesmo tempo que visa a melhor qualidade de vida possível" de tal modo que utilize instrumentos que levem em consideração a realidade social de cada indivíduo, como também, os pressupostos voltados à efetivação da possibilidade de que esse indivíduo tenha pleno acesso aos meios tidos como indispensáveis ao seu estado de bem-estar particular. Portanto, pode-se afirmar que a definição constitucional de saúde está diretamente relacionada à conceituação de qualidade de vida, ou seja, essas caminham lado a lado no panorama social, tornando-se possíveis por meio da aplicação de políticas públicas efetivas.

Por conseguinte, para atender aos ditames estabelecidos pela Constituição Federal ${ }^{14} \mathrm{e}$, simultaneamente, suprir as necessidades expostas pela população, as políticas públicas estatais precisam construir uma ampla aliança nacional e deter qualidade no que concerne à prestação dos serviços que visam a melhoria do bem-

\footnotetext{
$\overline{41}$ OMS - ORGANIZAÇÃO MUNDIAL DA SAÚDE. Constituição da Organização Mundial da Saúde (OMS/WHO) 1946. São Paulo: USP, Biblioteca Virtual de Direitos Humanos. Disponível em: http://www.direitoshumanos. usp.br/index.php/OMS-Organização-Mundial-da-Saúde/constituicao-da-organizacao-mundial-da-saudeomswho.html. Acesso em: 01 mar. 2018.

${ }^{42}$ BRASIL. Constituição da República Federativa do Brasil de 1988. Presidência da República. Disponível em: http://planalto.gov.br/ccivil_03/constituicao/constituicao.htm. Acesso em: 26 fev. 2018.

43 SCHWARTZ, Germano And̄ré Doederlein. Direito à Saúde: efetivação em uma perspectiva sistêmica. Porto Alegre: Livraria do Advogado, 2001. p. 43.

${ }^{44}$ BRASIL. Constituição da República Federativa do Brasil de 1988. Presidência da República. Disponível em: http://planalto.gov.br/ccivil_03/constituicao/constituicao.htm. Acesso em: 26 fev. 2018.
} 
estar social. Ou seja, devem centrar-se na qualidade de vida dos cidadãos do povo, a qual somente pode ser estabelecida por meio da aplicação adequada e equilibrada dos recursos econômicos por parte do poder público. Por meio disso, torna-se possível produzir indicadores de desempenho voltados para a avaliação do grau de efetividade da saúde, os quais podem gerar impactos nas áreas que se incidem. Para tanto, os padrões alvitrados devem ser observados por todos os órgãos públicos competentes (União, Estados e municípios), em virtude do envolvimento desses na consecução dos encargos que objetivam a proteção efetiva do direito fundamental à saúde pública na sociedade brasileira ${ }^{45}$.

Contudo, em que pese essas previsões e a oferta de serviços de acesso à saúde pelo Estado, pelo Sistema Único de Saúde e pelas entidades privadas (compreendidas pelos planos de saúde e operadoras), os cidadãos brasileiros têm considerado a saúde no Brasil bastante inefetiva, uma vez que a Constituição Federal de 1988 garante uma ampla diversidade de direitos e, muitas vezes, não as cumpre. Ademais, as políticas públicas e os programas de prevenção na área da saúde não dialogam entre si e, portanto, o usuário do sistema é visto tão somente em sua doença, razão pela qual, buscam-se no Judiciário, maneiras de auferir o direito à saúde na sociedade brasileira.

Nesse fenômeno, denominado de judicialização da saúde, as questões que são consideradas relevantes do ponto de vista social, político ou moral vêm sendo decididas pelo Poder Judiciário, em caráter final. Isto posto, trata-se de uma verdadeira transferência de poder do Estado para as instituições judiciais e, isso ocorre, em detrimento das tradicionais instâncias políticas: o Legislativo e o Executivo ${ }^{46}$. As primeiras ações judiciais que chegaram às cortes superiores, discutindo o direito à saúde, dataram meados da década de 1990, demandando essencialmente o direito subjetivo de acesso aos medicamentos e tratamentos que deveriam ser fornecidos por parte do poder público. Pode-se afirmar que desde então e, sobretudo, a partir dos anos 2000, o número de demandas judiciais vinculadas à proteção efetiva do

$\overline{45}$ OLIVEIRA, Gustavo Justino de. Efetivação do direito à saúde: ampliação do debate e renovação da agenda. Revista de Direito Sanitário, v. 16, n. 1, mar.jun., p. 78-86, 2015. Disponível em: http://dx.doi.org/10.11606/ issn.2316-9044.v16i1p78-86. Acesso em: 26 fev. 2018.

46 BARROSO, Luís Roberto. Constituição, democracia e supremacia judicial: direito e política no Brasil contemporâneo. RFD - Revista da Faculdade de Direito - UERJ, v. 2, n. 21, jan./jun. p. 1-50. 2012a. Disponível em: http://www.e-publicacoes.uerj.br/index.php/rfduerj/article/viewFile/1794/2297. Acesso em: 28 fev. 2018. 
direito à saúde cresceu exponencialmente ${ }^{47}$.

É evidente que presente temática em discussão envolve uma vasta gama de dificuldades, as quais têm início logo na separação dos poderes - que inúmeras vezes confundem-se, como no caso da intervenção do judiciário em questões de ordem política - e em seguida, perpassam pelo princípio da isonomia - que deveria garantir a igualdade de todos perante a lei, sem qualquer forma de distinção entre os cidadãos, para evitar as demandas judiciais que visam o auferir o dever prestacional da saúde por parte do poder público, quando submetidos apenas ao Sistema Único de Saúde (SUS) - . Posteriormente, os entraves evidenciam-se no princípio federativo, uma vez que cada ente federado detém responsabilidades específicas no tocante à prestação da saúde pública. Por fim, culmina-se em uma complexa ponderação dos bens e dos valores constitucionais, os quais estão conectados ao princípio da reserva do financeiramente possível, com o intuito de garantir o atendimento das necessidades, tanto no âmbito individual como no coletivo, desde que isso não prejudique as políticas públicas de saúde, ou, ainda, a execução das demais prioridades que se encontram previstas constitucionalmente ${ }^{48}$.

Em razão disso, no dia 05 de março de 2009, o STF convocou uma audiência pública ${ }^{49}$ contendo diversos segmentos da sociedade civil, a fim de discutir parâmetros para as decisões judiciais, visto que a quantidade excessiva de ações em matéria de medicamentos não mais poderia ser ignorada. Em pauta, o Supremo Tribunal Federal registrou a plena necessidade de se discutir a respeito da responsabilidade de todos os entes que compõe a federação brasileira em matéria de medicamentos/tratamentos a fim de assegurar a efetividade do direito à saúde em âmbito social. Além disso, entendeu que é de dever do Estado: I- fornecer aos pacientes a necessária prestação de saúde que é prescrita por médico que não se encontra incluso nos quadros do Sistema Único de Saúde (SUS); II- custear todas as

\footnotetext{
${ }^{47}$ BALESTRA NETO, Otávio. A jurisprudência dos Tribunais Superiores e o direito à saúde - evolução rumo à racionalidade. Revista de Direito Sanitário, v. 16, n. 1, mar./jun., p. 87-111. 2015. Disponível em: http://dx.doi. org/10.11606/issn.2316-9044.v16i1p87-111. Acesso em: 04 mar. 2018.

${ }^{48}$ VALLE, Gustavo Henrique Moreira do; CAMARGO, João Marcos Pires. A audiência pública sobre a judicialização da saúde e seus reflexos na jurisprudência do Supremo Tribunal Federal. Revista de Direito Sanitário, v. 11, n. 3, nov./fev., p. 13-31. 2011. Disponível em: http://dx.doi.org/10.11606/issn.2316-9044.v11i3p13-31. Acesso em: 01 mar. 2018.

49 Audiência Pública n. 4, realizada entre 27 de abril e 7 de maio de 2009, contou com depoimentos de pessoas com experiência e autoridade em relação ao SUS, contribuindo com o deslinde de questões técnicas, científicas, administrativas, políticas e econômicas envolvidas nas decisões judiciais sobre saúde. TF - SUPREMO TRIBUNAL FEDERAL. Audiência Pública. Brasília: STF, 2009. Disponível em: http://www.stf.jus. $\mathrm{br} / \mathrm{arquivo} / \mathrm{cms} / \mathrm{processoAudienciaPublicaSaude/anexo/Sr}$ __Min._Jose_Antonio_Dias_Toffoli_Advogado_ Geral_da_Uniao_.pdf. Acesso em: 28 fev. 2018.
} 
prestações de saúde que não são englobadas pelas políticas públicas vigentes; IIIdisponibilizar o acesso aos medicamentos e tratamentos considerados experimentais e que não estão registrados na Agência Nacional de Vigilância Sanitária (ANVISA) ou que, ainda, não são recomendados pelos regulamentos clínicos do SUS e; IVproporcionar medicamentos imprevistos e não licitados nas listas do SUS $^{50}$.

Impulsionado por essa audiência, o Conselho Nacional de Justiça (CNJ) criou um grupo de trabalho ${ }^{51}$ que acabou por instituir a recomendação $n$. $31^{52}$, de 30 de março de 2010, a qual traça diretrizes aos magistrados quanto às demandas judiciais que envolvem a assistência à saúde. Em 06 de abril de 2010, o CNJ publicou a resolução n. $107^{53}$, que instituiu o Fórum Nacional do Judiciário para monitoramento e resolução das demandas de assistência à saúde - Fórum da Saúde. Cumprindo a resolução n. 107, o CNJ disponibilizou em seu sítio eletrônico o número de ações de saúde que tramitavam nas mais diversas instâncias do Poder Judiciário: registrou-se que até junho de 2014 havia 62.291 ações na justiça federal e 330.630 nas justiças estaduais (com exceção dos tribunais dos Estados do Amazonas, Pernambuco e Paraíba, que não enviaram informações). O Estado do Rio Grande do Sul, por sua vez, liderava as demandas encaminhadas ao poder judiciário com 82 mil ações com pedidos de medicamentos e tratamentos de saúde, seguido pelo Estado de Minas Gerais que registrou 66.751 mil ações de saúde ${ }^{54}$.

Quanto às demandas judiciais, Fernando Facury Scaff e António José A. Nunes entendem que "não implica afirmar que o direito à saúde cumpre uma função meramente programática, sem efetividade e que não pode ter sua atuação submetida ao Judiciário" "55. É evidente que essa pretensão é exequível, no entanto, procura-se demonstrar que ao contrário de satisfazer todas as urgências relativas ao direito à saúde de uma maneira individualizada ou, ainda, para um grupo pequeno de pessoas, seria muito mais adequada a implementação de reformas/renovações estruturais e de

${ }^{50}$ BALESTRA NETO, Otávio. A jurisprudência dos Tribunais Superiores e o direito à saúde - evolução rumo à racionalidade. Revista de Direito Sanitário, v. 16, n. 1, mar./jun., p. 87-111, 2015. Disponível em: http://dx.doi. org/10.11606/issn.2316-9044.v16i1p87-111. Acesso em: 04 mar. 2018.

${ }^{51}$ Grupo instituído pela Portaria n. 650, de 20 de novembro de 2009 do Conselho Nacional de Justiça (CNJ).

52 CNJ - CONSELHO NACIONAL DE JUSTIÇA. Recomendação No 31 de 30/03/2010. Brasília-DF: CNJ, 2010. Disponível em: http://www.cnj.jus.br/busca-atos-adm?documento=2831. Acesso em: 02 mar. 2018.

53 CNJ - CONSELHO NACIONAL DE JUSTIÇA. Resolução No 107 de 06/04/2010. Brasília-DF: CNJ, 2010. Disponível em: http://www.cnj.jus.br/busca-atos-adm?documento=2831. Acesso em: 02 mar. 2018.

${ }^{54}$ CNJ - CONSELHO NACIONAL DE JUSTIÇA. Fórum da Saúde. Brasília-DF: CNJ, 2018. Disponível em: http:// www.cnj.jus.br/index.php?option = com_content\&view $=$ article\&catid $=1 \% 3$ Anotas\&id $=13433 \% 3$ Aprojetocapacita-professores-como-multiplicadores-de-cidadania-e-justica\&Itemid=169. Acesso em: 02 mar. 2018.

55 SCAFF, Fernando Facury; NUNES, António José Avelãs. Os Tribunais e o Direito à Saúde. Porto Alegre: Livraria do Advogado, 2011. p. 129. 
políticas públicas de saúde que possam, de fato, serem efetivadas sem a necessidade de ingerência do Poder Judiciário. Nesse sentido, é o entendimento de Barroso ao afirmar que "o Judiciário quase sempre pode, mas nem sempre deve interferir. Ter uma avaliação criteriosa da própria capacidade institucional e optar por não exercer o poder, em autolimitação espontânea, antes eleva do que diminui" ${ }^{56}$.

Desta forma, saber o momento específico da intervenção judicial é de suma relevância. Eduardo Appio ressalta que, no processo de formulação de políticas públicas, o controle dependerá do modelo político de participação popular adotado. Já na fase de execução dessas políticas, a intervenção dependerá “[...] dos atores sociais diretamente afetados pelas medidas governamentais, fundamentalmente a partir da exigência de um tratamento isonômico por parte da Administração Pública" $"$.

Ou seja, "os riscos da judicialização excessiva envolvem a legitimidade democrática, a politização da justiça e a falta de capacidade institucional do Judiciário para decidir determinadas matérias" ${ }^{\prime 5}$. O que se observa, enfim, é que existe um grande número de ações que são necessárias a apreciação pelo judiciário e outras que não precisariam movimentar a máquina pública, uma vez que poderiam ser resolvidas pela administração em processo administrativo. Outro ponto que precisa ser observado nas decisões judiciais em matéria de medicamentos é, justamente, o excessivo aumento de decisões extravagantes ou emotivas, que levam a administração pública a custear tratamentos inconvenientes, seja pela inacessibilidade ou por serem destituídos de essencialidade.

Nesse sentido, Ada Pelegrini Grinover, conhecida por defender as políticas públicas pelo Poder Judiciário, alerta sobre os abusos de uma intervenção judicial fragmentada em casos particulares de tutela de interesses individuais, que não compreenda o caráter coletivo das ações governamentais ${ }^{59}$. Por isso, a referida autora propõe limites ou requisitos para a intervenção do Poder Judiciário, com base na

\footnotetext{
${ }^{56}$ BARROSO, Luís Roberto. Judicialização, ativismo judicial e legitimidade democrática. (Syn) Thesis, v. .5, n. 1, p. 23-32, 2012b. Disponível em: http://www.e-publicacoes.uerj.br/index.php/synthesis/article/view/7433/5388. Acesso em: 03 mar. 2018. p. 30.

${ }^{57}$ APPIO, Eduardo. Controle das políticas públicas no Brasil. Curitiba: Juruá, 2008. p. 105.

${ }^{58}$ BARROSO, Luís Roberto. Judicialização, ativismo judicial e legitimidade democrática. (Syn)Thesis, v. 5, n. 1, p. 23-32, 2012b. Disponível em: http://www.e-publicacoes.uerj.br/index.php/synthesis/article/view/7433/5388. Acesso em: 03 mar. 2018. p. 31.

${ }^{59}$ GRINOVER, Ada Pellegrini. O controle das políticas públicas pelo Poder Judiciário. Revista do Curso de Direito da Faculdade de Humanidades e Direito da Universidade Metodista de São Paulo, v. 7, n. 7, p. 9-37, 2010. Disponível em: https://www.metodista.br/revistas/revistas-ims/index.php/RFD/article/view/1964/1969. Acesso em: 03 mar. 2018.
} 
jurisprudência do STF: garantia do mínimo existencial, razoabilidade da pretensão deduzida em juízo e existência de disponibilidade financeira do Estado, a "reserva do possível" somente oponível se comprovada a ausência de recursos orçamentários. Ressalta-se que se observados esses requisitos, desde que acompanhados da aplicação efetiva das políticas públicas de saúde existentes na sociedade brasileira, já seria suficiente para conter o excesso das demandas judiciais de saúde em matéria de medicamentos/tratamentos e, inclusive, isso contribuiria para a redução do elevado ônus do erário público por meio da observação do princípio da reserva do possível e da limitação da intervenção judicial.

Além disso, segundo Grinover "uma política pública razoável (e, portanto, adequada) deve propiciar o atendimento ao maior número de pessoas com o mesmo volume de recursos" ${ }^{0}$, merecendo críticas portanto, alguns julgados que não atendem os critérios da razoabilidade e concedem ao autor: medicamentos que, de fato, não constam nas listas oficiais de distribuição gratuita do SUS, tratamentos com um valor bastante elevado no exterior ou, ainda, a aquisição de remédios experimentais específicos que sequer foram liberados pela Agência Nacional de Vigilância Sanitária (ANVISA) para comercialização no Brasil. Por tais motivos, as decisões jurídicas exigem uma análise bastante técnica, fato que pressupõe que quanto maior for considerado o nível técnico estabelecido para o exame de determinada matéria, menor ainda deve ser a intervenção judiciária em um âmbito que não lhes compete. Assim, deve-se buscar a observância de limites à intervenção judicial, bem como o exato conceito de políticas públicas (com programas e ações tendentes ao atendimento dos objetivos do Estado brasileiro) para conter essas arbitrariedades abusivas.

Contudo, ficou decidido em sede recursal do Superior Tribunal de Justiça (STJ) que, excepcionalmente, quando for verificada uma situação em que o tratamento fornecido pelo Sistema Único de Saúde (SUS) não é considerado adequado ao paciente e, mediante a plena comprovação do caso hipotético em que há a incapacidade financeira de arcar com o custo do medicamento prescrito e a existência de registro na ANVISA do medicamento, será possível que o judiciário condene à administração pública ao cumprimento do dever prestacional desse

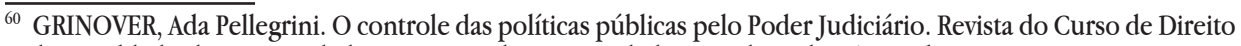
da Faculdade de Humanidades e Direito da Universidade Metodista de São Paulo, v. 7, n. 7, p. 9-37, 2010. Disponível em: https://www.metodista.br/revistas/revistas-ims/index.php/RFD/article/view/1964/1969. Acesso em: 03 mar. 2018. p. 25. 
tratamento específico. Foi o que ocorreu no Recurso Especial 1657156 do Rio de Janeiro, julgado em abril de 2018 pela Primeira Seção do Superior Tribunal de Justiça, como recurso repetitivo, servindo de base para todas as situações demandadas em que consta que o tratamento oferecido pelo SUS não é apropriado e eficaz, devendo, portanto, o Estado viabilizar outra alternativa de terapêutica que garanta a efetividade do direito à saúde. Dessa forma, segue a decisão do REsp 1657156/RJ.

ADMINISTRATIVO. RECURSO ESPECIAL REPRESENTATIVO DE CONTROVÉRSIA. TEMA 106. JULGAMENTO SOB O RITO DO ART. 1.036 DO CPC/2015. FORNECIMENTO DE MEDICAMENTOS NÃO CONSTANTES DOS ATOS NORMATIVOS DO SUS. POSSIBILIDADE. CARÁTER EXCEPCIONAL. REQUISITOS CUMULATIVOS PARA O FORNECIMENTO. 1. Caso dos autos: A ora recorrida, conforme consta do receituário e do laudo médico (fls. 1415, e-STJ), é portadora de glaucoma crônico bilateral (CID 440.1), necessitando fazer uso contínuo de medicamentos (colírios: azorga $5 \mathrm{ml}$, glaub $5 \mathrm{ml}$ e optive $15 \mathrm{ml}$ ), na forma prescrita por médico em atendimento pelo Sistema Único de Saúde - SUS. A Corte de origem entendeu que foi devidamente demonstrada a necessidade da ora recorrida em receber a medicação pleiteada, bem como a ausência de condições financeiras para aquisição dos medicamentos. 2. Alegações da recorrente: Destacou-se que a assistência farmacêutica estatal apenas pode ser prestada por intermédio da entrega de medicamentos prescritos em conformidade com os Protocolos Clínicos incorporados ao SUS ou, na hipótese de inexistência de protocolo, com o fornecimento de medicamentos constantes em listas editadas pelos entes públicos. Subsidiariamente, pede que seja reconhecida a possibilidade de substituição do medicamento pleiteado por outros já padronizados e disponibilizados. 3. Tese afetada: Obrigatoriedade do poder público de fornecer medicamentos não incorporados em atos normativos do SUS (Tema 106). Trata-se, portanto, exclusivamente do fornecimento de medicamento, previsto no inciso I do art. 19-M da Lei $\mathrm{n}$. 8.080/1990, não se analisando os casos de outras alternativas terapêuticas. 4. TESE PARA FINS DO ART. 1.036 DO CPC/2015 A concessão dos medicamentos não incorporados em atos normativos do SUS exige a presença cumulativa dos seguintes 
requisitos: (i) Comprovação, por meio de laudo médico fundamentado e circunstanciado expedido por médico que assiste o paciente, da imprescindibilidade ou necessidade do medicamento, assim como da ineficácia, para o tratamento da moléstia, dos fármacos fornecidos pelo SUS; (ii) incapacidade financeira de arcar com o custo do medicamento prescrito; (iii) existência de registro na ANVISA do medicamento. 5. Recurso especial do Estado do Rio de Janeiro não provido. Acórdão submetido à sistemática do art. 1.036 do CPC/2015. (STJ - REsp: 1657156 RJ 2017/0025629-7, Relator: Ministro BENEDITO GONÇALVES, Data de Julgamento: 25/04/2018, S1 - PRIMEIRA SEÇÃO, Data de Publicação: DJe 04/05/2018). ${ }^{61}$

Nesse contexto, as demandas judiciais são consideradas grandes desafios para o SUS. Em audiência pública sobre a judicialização da saúde realizada no Conselho Nacional de Justiça (CNJ), o secretário de controle externo, Marcelo André Barboza da Rocha afirmou que "os gastos da União e dos Estados cresceram 1.300\% devido às demandas judiciais para fornecimento de medicamentos entre 2008 a $2015{ }^{\circ 2}$ gerando uma despesa que saltou de $\mathrm{R} \$ 70$ milhões para $\mathrm{R} \$ 1$ bilhão. De acordo com o acordão do Tribunal de Contas da União (TCU) ${ }^{63}$, a maior parte dos gastos com medicamentos não se refere a itens incorporados ao Sistema Único de Saúde. Desse modo, Schwartz afirma que "dentro do caráter sistêmico da saúde, a procura pela sua efetivação/solução não é problema apenas do Judiciário ou de um único estamento social" ${ }^{64}$, muito pelo contrário, essa é considerada um desafio para todos as instâncias do poder estatal e componentes da sociedade, isso porque, o problema da inefetividade da saúde pública abrange "a todos os integrantes de uma nação, possuindo característica interdisciplinar e holística" ${ }^{65}$.

${ }_{61}$ STJ - Superior Tribunal de Justiça. Recurso Especial Representativo de Controvérsia - REsp: 1657156 RJ 2017/0025629-7. Relator:MinistroBeneditoGonçalves. Brasília-DF:STJ,04mai.2018. Disponívelem:http://www. stj.jus.br/SCON/jurisprudencia/doc.jsp?livre $=1657156 \& b=A C O R \& p=$ true \&t $=J U R I D I C O \& l=10 \& i=7$. Acesso em: 10 mai. 2018.

${ }^{62}$ CNJ - CONSELHO NACIONAL DE JUSTIÇA. TCU e Estados apontam aumento dos gastos com a judicialização da saúde. Escrito por Luiza Fariello. Agência, Brasília: CNJ de Notícias, dez. 2017. Disponível em: http:// www.cnj.jus.br/noticias/cnj/85911-tcu-e-estados-apontam-aumento-dos-gastos-com-a-judicializacao-da-saude. Acesso em: 05 mar. 2018. s.p.

${ }^{63}$ CNJ - CONSELHO NACIONAL DE JUSTIÇA. TCU e Estados apontam aumento dos gastos com a judicialização da saúde. Escrito por Luiza Fariello. Agência, Brasília: CNJ de Notícias, dez. 2017. Disponível em: http:// www.cnj.jus.br/noticias/cnj/85911-tcu-e-estados-apontam-aumento-dos-gastos-com-a-judicializacao-da-saude. Acesso em: 05 mar. 2018.

${ }^{64}$ SCHWARTZ, Germano André Doederlein. Direito à Saúde: efetivação em uma perspectiva sistêmica. Porto Alegre: Livraria do Advogado, 2001. p. 156.

${ }^{65}$ Idem. 
Acerca dessa problemática, Daniel Wunder Hachem esclarece que, especialmente no âmbito da saúde, os tribunais passaram, cada vez mais, a conceder "prestações estatais postuladas individualmente, satisfazendo o direito daqueles que logravam acesso ao Poder Judiciário, mas sem resolver o problema da vasta maioria das classes marginalizadas da população" ${ }^{\prime 6}$. Nessa circunstância, tais decisões que garantem o fornecimento de muitos medicamentos (os quais não estão dispostos nas listas oficiais de distribuição gratuita no Brasil) em virtude da condenação estatal, também acabam, por vezes, prejudicando o Estado, em razão da existência evidente de uma "dificuldade orçamentária, da conjuntura política ou da ausência ou inadequação de instrumentos normativos capazes de dar concretude às respectivas decisões" ${ }^{\prime \prime}$.

Dessa forma, as decisões judiciais sempre devem ser vistas em cada caso concreto e aplicadas à realidade brasileira, ou seja, devem ser analisadas todas as políticas públicas existentes e o orçamento elaborado pelo Estado para suprir essas novas exigências em relação à saúde, garantindo o bem-estar da população bem como o acesso de todos os usuários ao sistema. Busca-se, então, o estabelecimento de parâmetros e critérios que estejam adequados tanto ao cidadão que busca o atendimento universal e igualitário quanto à exigência dada ao Poder Público para que satisfaça o direito humano fundamental à saúde.

Nesse sentido, destaca-se a existência de um grande desafio a ser enfrentado com relação aos excessos e os custos crescentes da judicialização para o sistema público de saúde, decorrentes dos anseios populacionais em ter acesso às tecnologias novas ou inovadoras oferecidas pela indústria farmacêutica. Tecnologias tão caras que, eficazes ou não, têm sido acolhidas no país, em nome do princípio da universalidade da cobertura, da diretriz da integralidade do tratamento e da especificidade do mercado da saúde, que opera produtos de valores inestimáveis: a vida dos seres humanos e a qualidade de vida.

Assim, é verificável que de um lado encontra-se a administração pública, a qual evidencia que a insuficiência dos recursos econômicos precisa atender todas as necessidades sociais e, inclusive, deve seguir as leis e os princípios jurídicos, buscando

\footnotetext{
${ }_{66}$ HACHEM, Daniel Wunder. Tutela administrativa efetiva dos direitos fundamentais sociais: por uma implementação espontânea, integral e igualitária. 2014. Tese (Doutorado) - Universidade Federal do Paraná UFPR, Curitiba, 2014. Disponível em: http://hdl.handle.net/1884/35104. Acesso em 02 mar. 2018. p. 2.

${ }^{67}$ COSTA, Bruno Andrade. O controle judicial nas políticas públicas: análise das decisões judiciais e seu cumprimento para a realização progressiva dos direitos fundamentais sociais. RIL - Revista de Informação Legislativa, v. 50, n. 199, jul./set., p. 255-269, 2013. Disponível em: https://www12.senado.leg.br/ril/ edicoes/50/199/ril_v50_n199_p255.pdf. Acesso em: 03 mar. 2018. p. 260.
} 
com isso a macrojustiça; de outro lado encontra-se o judiciário que, por sua vez, entende o direito à saúde como exclusivamente integral e universal, sem levar em consideração as políticas públicas já formuladas, buscando com isso a microjustiça. Portanto, conclui-se que um pleno equilíbrio existente entre a dimensão individual e coletiva do direito à saúde na sociedade brasileira da atualidade ainda parece estar bastante longe de ser alcançado.

\section{CONSIDERAÇÕES FINAIS}

Frente ao panorama da contemporaneidade, pré-estabelecido nas últimas décadas do século XX e início do século XXI, verifica-se a existência de significativos desafios pressupostos pela temática do presente artigo, o qual perfez a análise da problemática do risco da inefetividade do direito à saúde e o correspondente aumento exponencial da judicialização das demandas em matéria de medicamentos/ tratamentos, utilizando-se, para tanto, de uma abordagem sistêmica social. A preocupação e o senso de responsabilidade com relação à saúde remetem-se aos primórdios da humanidade até as sociedades atuais. Isso porque, em qualquer período da história civilizacional, a saúde sempre foi encarada como um elemento de fundamental relevância, seja pelas ameaças das doenças ou pelo medo da morte que, de certo modo, intensificaram-se com a emergência de uma sociedade complexa e globalizada.

Conforme foi estudado, a saúde pode ser compreendida como um sistema social diferenciado, operativamente fechado e cognitivamente aberto, tendo por base o referencial teórico pragmático-sistêmico de Niklas Luhmann, o qual demonstra a impossibilidade de compreender o referido sistema da saúde de uma forma estática, em virtude da comunicabilidade com os demais tecidos societais. Daí parte a fundamental conveniência de tratar o acoplamento estrutural entre o sistema da saúde e o sistema jurídico com especial relevância, uma vez que as irritações mútuas entre esses possibilitam a elaboração das normas voltadas à proteção efetiva do direito à saúde, elemento considerado necessário para a garantia da cidadania de todos do povo em ter acesso a um dever prestacional que precisa ser assegurado pelo Estado. De fato, o direito à saúde, previsto na Constituição Federal brasileira de 1988 (art. 196), deve ser universal e igualitário em prol da qualidade de vida digna da população, no entanto, verifica-se que a sua efetivação se depara com inúmeros 
impasses pela ausência de recursos públicos, pela insuficiência e descumprimento das políticas públicas e, inclusive, pela constatação de uma administração frágil e insatisfatória.

Em razão disso, nota-se que os cidadãos buscam no judiciário maneiras de alcançar o direito à saúde. Em diversos aspectos, as ações judiciais são plenamente justificáveis e, muitas vezes, mais do que necessárias. Atualmente, há um número significativamente elevado de demandas de saúde em matéria de medicamentos, fato que sobrecarrega o Poder Judiciário. Desse modo, deve-se identificar os limites e as possibilidades em relação à judicialização da saúde, afinal, pode-se afirmar que o imoderado deferimento judicial que condena a administração pública ao fornecimento de tratamentos e medicamentos com um grau de onerosidade elevado - e nem sempre essenciais -, pode ocasionar danos expressivos e prejudicar como um todo o Estado democrático e social de direito, inviabilizando o planejamento de utilização das finanças públicas.

Constata-se, ainda, que a prescrição médica individual, a hipossuficiência econômica e a urgência dos demandantes em acessar os medicamentos/tratamentos consistem nos principais respaldos das decisões judiciais que determinam o fornecimento desses conforme o requerido pelos autores das ações. Nesse sentido, apesar do evidente dever estatal de garantir a efetividade do direito à saúde, ressaltase que essa obrigação precisa ser realizada de um modo planejado e equilibrado com o orçamento público e a reserva do possível. Por conseguinte, tanto a eficácia como a efetivação da saúde requerem um conjunto de respostas políticas e ações governamentais mais amplas e não meramente formais e restritas às ordens judiciais, capazes de suprir as lacunas da inadequação organizacional na gestão dos poderes e dos recursos econômicos, tendo em vista a aplicação do direito à saúde frente às necessidades sociais. Assim, deve-se buscar a melhor qualidade de vida possível dentre os inúmeros fatores que limitam a consecução do direito à saúde, que está estritamente atrelado à vontade política.

Por fim, fica evidente a fundamental relevância da conceituação da saúde como um processo sistêmico que, além de objetivar a cura e a prevenção de enfermidades, visa, ao mesmo tempo, à melhor qualidade de vida para os indivíduos que precisam adaptar-se à hipercomplexidade da contemporaneidade. À vista disso, torna-se necessária a projeção de um novo horizonte de possibilidades no que concerne ao aprimoramento dos recursos teórico-metodológicos, científicos, 
políticos e econômicos, de tal modo que exista uma igualdade plena para a garantia da promoção efetiva do direito fundamental à saúde enquanto um valor universal, redefinido em uma perspectiva teórica sistêmica e voltado para a valorização da vida e para o respeito da dignidade da pessoa humana em âmbito social.

\section{REFERÊNCIAS}

APPIO, Eduardo. Controle das políticas públicas no Brasil. Curitiba: Juruá, 2008.

BALESTRA NETO, Otávio. A jurisprudência dos Tribunais Superiores e o direito à saúde - evolução rumo à racionalidade. Revista de Direito Sanitário, v. 16, n. 1, mar./jun., p. 87-111, 2015. Disponível em: http://dx.doi.org/10.11606/issn.23169044.v16i1p87-111. Acesso em: 04 mar. 2018.

BARROSO, Luís Roberto. Constituição, democracia e supremacia judicial: direito e política no Brasil contemporâneo. RFD - Revista da Faculdade de Direito - UERJ. Vol. 2, n. 21, jan./jun., p. 1-50, 2012a. Disponível em: http://www.e-publicacoes. uerj.br/index.php/rfduerj/article/viewFile/1794/2297. Acesso em: 28 fev. 2018.

BARROSO, Luís Roberto. Judicialização, ativismo judicial e legitimidade democrática. (Syn)Thesis, v. 5, n. 1, p. 23-32, 2012b. Disponível em: http://www.epublicacoes.uerj.br/index.php/synthesis/article/view/7433/5388. Acesso em: 03 mar. 2018.

BECK, Ulrich. Sociedade de risco mundial: em busca da segurança perdida. Tradução de Marian Toldy e Teresa Toldy. Lisboa: Edições 70, 2015.

BEDIN, Gilmar Antonio. A sociedade internacional e o século XXI: em busca da construção de uma ordem mundial justa e solidária. Ijuí: Unijuí, 2001.

BRASIL. Constituição da República Federativa do Brasil de 1988. Presidência da República. Disponível em: http://planalto.gov.br/ccivil_03/constituicao/ constituicao.htm. Acesso em: 26 fev. 2018.

CAPRA, Fritjof; LUISI, Pier Luigi. A visão sistêmica da vida: uma concepção unificada e suas implicações filosóficas, políticas, sociais e econômicas. Tradução de Mayra Teruya Eichemberg e Newton Roberval Eichemberg. São Paulo: Cultrix, 2014. 
CNJ - CONSELHO NACIONAL DE JUSTIÇA. Fórum da Saúde. Brasília-DF: CNJ, 2018. Disponível em: http://www.cnj.jus.br/index.php?option=com_content\&vie $\mathrm{w}=$ article\&catid $=1 \% 3$ Anotas\&id $=13433 \% 3$ Aprojeto-capacita-professores-comomultiplicadores-de-cidadania-e-justica\&Itemid=169. Acesso em: 02 mar. 2018.

CNJ - CONSELHO NACIONAL DE JUSTIÇA. Recomendação No 31 de 30/03/2010. Brasília-DF: CNJ, 2010. Disponível em: http://www.cnj.jus.br/busca-atosadm?documento=2831. Acesso em: 02 mar. 2018.

CNJ - CONSELHO NACIONAL DE JUSTIÇA. Resolução No 107 de 06/04/2010. Brasília-DF: CNJ, 2010. Disponível em: http://www.cnj.jus.br/busca-atosadm?documento $=2831$. Acesso em: 02 mar. 2018.

CNJ - CONSELHO NACIONAL DE JUSTIÇA. TCU e Estados apontam aumento dos gastos com a judicialização da saúde. CNJ de Notícias, Brasília, dez. 2017. Disponível em: http://www.cnj.jus.br/noticias/cnj/85911-tcu-e-estados-apontamaumento-dos-gastos-com-a-judicializacao-da-saude. Acesso em: 05 mar. 2018.

COSTA, Bruno Andrade. O controle judicial nas políticas públicas: Análise das decisões judiciais e seu cumprimento para a realização progressiva dos direitos fundamentais sociais. RIL - Revista de Informação Legislativa, v. 50, n. 199, jul./set., p. 255-269, 2013. Disponível em: https://www12.senado.leg.br/ril/ edicoes/50/199/ril_v50_n199_p255.pdf. Acesso em: 03 mar. 2018.

CURY, Ieda Tatiana. Direito fundamental à saúde: Evolução, Normatização e Efetividade. Rio de Janeiro: Lumen Juris, 2005.

FARIA, José Eduardo. O direito na economia globalizada. São Paulo: Malheiros Ed., 2002.

FIGUEIREDO, Mariana Filchtiner. Direito fundamental à saúde: parâmetros para sua eficácia e efetividade. Porto Alegre: Livraria do Advogado, 2007.

GRINOVER, Ada Pellegrini. O controle das políticas públicas pelo Poder Judiciário. Revista do Curso de Direito da Faculdade de Humanidades e Direito da Universidade Metodista de São Paulo, v. 7, n. 7, p. 9-37, 2010. Disponível em: https://www.metodista.br/revistas/revistas-ims/index.php/RFD/article/ view/1964/1969. Acesso em: 03 mar. 2018. 
HACHEM, Daniel Wunder. Tutela administrativa efetiva dos direitos fundamentais sociais: por uma implementação espontânea, integral e igualitária. Tese (doutorado) - Universidade Federal do Paraná - UFPR, Curitiba, 2014. Disponível em: http:/hdl.handle.net/1884/35104. Acesso em 02 mar. 2018.

IANNI, Octavio. A sociedade global. Rio de Janeiro: Civilização Brasileira, 1996.

LUHMANN, Niklas. El derecho de la sociedad. Tradução de Javier Torres Nafarrate. México: Herder, 2005.

LUHMANN, Niklas. O Enfoque Sociológico da Teoria e Prática do Direito. Tradução de Cristiano Paixão, Daniela Nicola e Samantha Dobrowolski. Sequência. Estudos Jurídicos e Políticos - PPGD UFSC. n. 28, jun., p. 15-29. Disponível em: https:// periodicos.ufsc.br/index.php/sequencia/article/view/15871/14360. Acesso em: 02 mar. 2018.

LUHMANN, Niklas. Sociología del Riesgo. México: Universidad Iberoamericana, 1992. Disponível em: 2018.

LUIZ, Olinda do Carmo; COHN, Amélia. Sociedade de risco e risco epidemiológico. Cadernos de Saúde Pública, Rio de Janeiro, v. 22, n. 11, p. 2339-2348, 2006. Disponível em: http://dx.doi.org/10.1590/S0102-311X2006001100008. Acesso em: 04 mar. 2018.

OLIVEIRA, Gustavo Justino de. Efetivação do direito à saúde: ampliação do debate e renovação da agenda. Revista de Direito Sanitário, v. 16, n. 1, p. 78-86, mar./ jun. 2015. Disponível em: http://dx.doi.org/10.11606/issn.2316-9044.v16i1p78-86. Acesso em: 26 fev. 2018.

OMS - ORGANIZAÇÃO MUNDIAL DA SAÚDE. Constituição da Organização Mundial da Saúde (OMS/WHO) - 1946. Disponível em: http://www. direitoshumanos.usp.br/index.php/OMS-Organização-Mundial-da-Saúde/ constituicao-da-organizacao-mundial-da-saude-omswho.html. Acesso em: 01 mar. 2018.

SARLET, Ingo Wolfgang. A eficácia dos direitos fundamentais: uma teoria geral dos direitos fundamentais na perspectiva constitucional. 10. ed. rev. atual. e ampl. Porto Alegre: Livraria do Advogado, 2009. 
SCAFF, Fernando Facury; NUNES, António José Avelãs. Os Tribunais e o Direito à Saúde. Porto Alegre: Livraria do Advogado, 2011.

SCHWARTZ, Germano André Doederlein. Direito à Saúde: efetivação em uma perspectiva sistêmica. Porto Alegre: Livraria do Advogado, 2001.

SCHWARTZ, Germano André Doederlein. O tratamento jurídico do risco no direito à saúde. Porto Alegre: Livraria do Advogado, 2004.

STF - SUPREMO TRIBUNAL FEDERAL. Audiência Pública. Brasília: STF, 2009. Disponível em: http://www.stf.jus.br/arquivo/cms/processoAudienciaPublicaSaude/ anexo/Sr._Min._Jose_Antonio_Dias_Toffoli_Advogado_Geral_da_Uniao_.pdf. Acesso em: 28 fev. 2018.

STJ - Superior Tribunal de Justiça. Recurso Especial Representativo de Controvérsia - REsp: 1657156 RJ 2017/0025629-7. Relator: Ministro Benedito Gonçalves. Brasília - DF: STJ, 04 maio 2018. Disponível em: http://www.stj.jus.br/SCON/jurisprudencia/doc. jsp?livre $=1657156 \& \mathrm{~b}=\mathrm{ACOR} \& \mathrm{p}=$ true $\& \mathrm{t}=\mathrm{JURIDICO} \& \mathrm{l}=10 \& \mathrm{i}=7$. Acesso em $: 10$ mai. 2018.

TEUBNER, Gunther. Fragmentos Constitucionais: constitucionalismo social na globalização. São Paulo: Saraiva, 2016.

TEUBNER, Gunther. O Direito como Sistema Autopoiético. Tradução de José Engrácia Antunes. Lisboa: Fundação Calouste Gulbenkian, 1993.

VALLE, Gustavo Henrique Moreira do; CAMARGO, João Marcos Pires. A audiência pública sobre a judicialização da saúde e seus reflexos na jurisprudência do Supremo Tribunal Federal. Revista de Direito Sanitário, v. 11, n. 3, nov./ fev. p. 13-31, 2011. Disponível em: http://dx.doi.org/10.11606/issn.2316-9044. v11i3p13-31. Acesso em: 01 mar. 2018.

VIAL, Sandra Regina Martini. Construção do sistema social da saúde a partir da Teoria Sistêmica de Niklas Luhmann. Revista de Direito Sanitário, v.16, n.1, mar./ jun., p. 112-127, 2015. Disponível em: http://dx.doi.org/10.11606/issn.2316-9044. v16i1p112-127. Acesso em: 27 fev. 2018. 
VIAL, Sandra Regina Martini. O sistema social da saúde: conceito, limites e possibilidades. Cadernos Ibero-Americanos de Direito Sanitário, v. 3, n. 1, jan./jun., p. 68-83, 2014. Disponível em: http://dx.doi.org/10.17566/ciads.v3i1.19. Acesso em: 28 fev. 2018.

Recebido em: 01/11/2018

Aceito em: 02/08/2019 